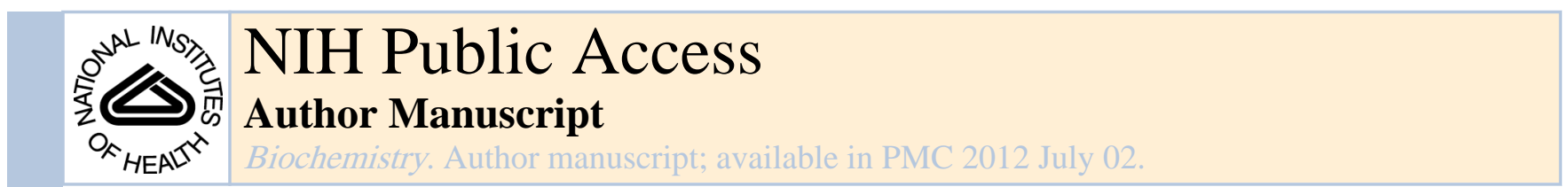

Published in final edited form as:

Biochemistry. 2011 November 29; 50(47): 10300-10310. doi:10.1021/bi2009147.

\title{
Heat Shock Protein 70 Prevents both Tau Aggregation and the Inhibitory Effects of Preexisting Tau Aggregates on Fast Axonal Transport
}

Kristina R. Patterson ${ }^{\star}, \dagger \neq$, Sarah M. Ward ${ }^{\dagger} \ddagger$, Benjamin Combs ${ }^{\S}$, Kellen Voss ${ }^{\S}$, Nicholas M. Kanaan $^{\ddagger}, \|$, Gerardo Morfini ${ }^{\ddagger, \perp}$, Scott T. Brady ${ }^{\ddagger}, \perp$, T. Chris Gamblin ${ }^{\S}$, and Lester I. Binder ${ }^{\dagger}$ tDepartment of Cell and Molecular Biology, Feinberg School of Medicine, Northwestern University, Chicago, Illinois 60611, United States

¥Marine Biological Laboratory, Woods Hole, Massachusetts 02543, United States

$\S$ Department of Molecular Biosciences, University of Kansas, Lawrence, Kansas 66045, United States

"Department of Translational Science and Human Medicine, Van Andel Institute, Michigan State University, Grand Rapids, Michigan 49503, United States

${ }^{\perp}$ Department of Anatomy and Cell Biology, University of Illinois at Chicago, Chicago, Illinois 60612, United States

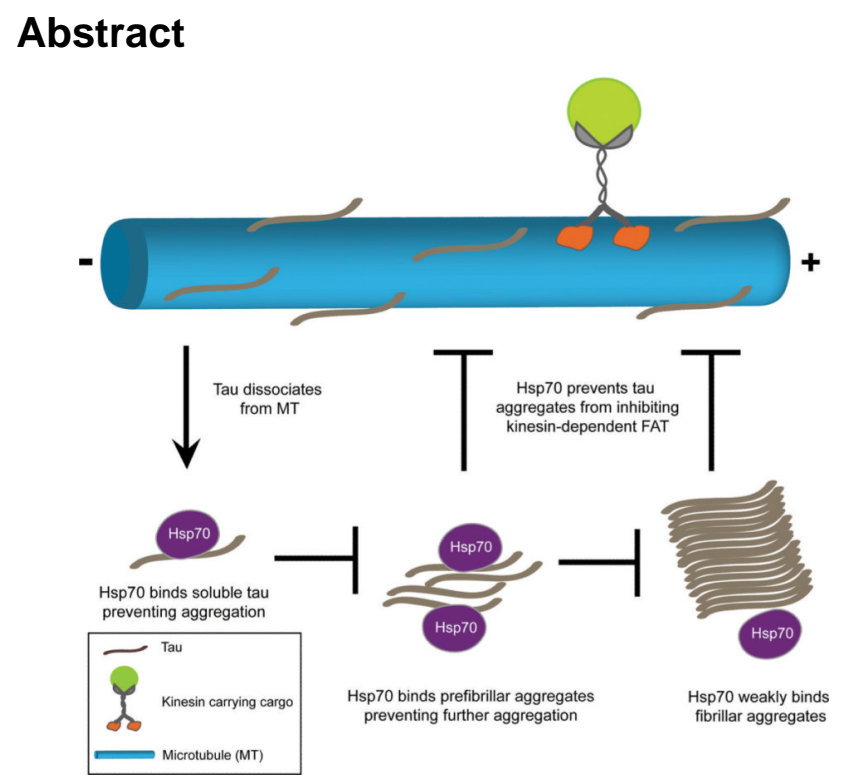

(C) 2011 American Chemical Society

*Corresponding Author Address: 303 E. Chicago Ave., Tarry 8-754, Chicago, IL 60611. Telephone: (312) 503-0824. Fax: (312) 503-7912. k-patterson@md.northwestern.edu..

Supporting Information A figure illustrating the identification and removal of the chaperone DnaK from recombinant tau preparations and the effect of this chaperone on tau aggregation. This material is available free of charge via the Internet at http://pubs.acs.org.

ADDITIONAL NOTE ${ }^{a}$ The critical concentration of hTau 40 for polymerization is estimated to be approximately $0.9 \mu \mathrm{M}$ for AAstimulated aggregation as measured using LLS. ${ }^{38}$ Thus, if Hsp70 were inhibiting tau aggregation by binding only to monomeric tau, we would expect the $\mathrm{IC}_{50}$ to be approximately $550 \mathrm{nM}$. 
Aggregation and accumulation of the microtubule-associated protein tau are associated with cognitive decline and neuronal degeneration in Alzheimer's disease and other tauopathies. Thus, preventing the transition of tau from a soluble state to insoluble aggregates and/or reversing the toxicity of existing aggregates would represent a reasonable therapeutic strategy for treating these neurodegenerative diseases. Here we demonstrate that molecular chaperones of the heat shock protein 70 (Hsp70) family are potent inhibitors of tau aggregation in vitro, preventing the formation of both mature fibrils and oligomeric intermediates. Remarkably, addition of Hsp70 to a mixture of oligomeric and fibrillar tau aggregates prevents the toxic effect of these tau species on fast axonal transport, a critical process for neuronal function. When incubated with preformed tau aggregates, Hsp70 preferentially associated with oligomeric over fibrillar tau, suggesting that prefibrillar oligomeric tau aggregates play a prominent role in tau toxicity. Taken together, our data provide a novel molecular basis for the protective effect of Hsp70 in tauopathies.

Tau is a microtubule-associated protein predominantly expressed in axons where it is involved in the maintenance and stabilization of microtubules. ${ }^{1}$ Under physiological conditions, tau is a soluble protein with limited secondary structure. ${ }^{2}$ However, in Alzheimer's disease (AD), tau dissociates from microtubules and self-associates to form both fibrillar and prefibrillar oligomeric aggregates. ${ }^{3,4}$ Aggregated forms of tau are also found in various other tauopathies, including Pick's disease, corticobasal degeneration, and progressive supranuclear palsy. ${ }^{5}$ Importantly, the identification of mutations in the tau gene that cause hereditary tauopathies demonstrates that tau dysfunction is sufficient to cause neuronal degeneration.

Neurofibrillary tangles (NFTs), a pathological hallmark of AD and other tauopathies, are composed of fibrillar tau aggregates and positively correlate with cognitive decline. ${ }^{6}$

However, recent evidence suggests that prefibrillar oligomeric tau aggregates may represent the main toxic species. ${ }^{7}$ For instance, neurodegeneration occurs in some tau overexpression animal models that lack overt neurofibrillary pathology. ${ }^{8,9}$ Another study demonstrated that levels of early multimeric tau aggregates that preceded neurofibrillary pathology correlated better with memory deficits. ${ }^{10}$ Moreover, suppression of tau expression improved memory function without affecting existing NFTs. ${ }^{11,12}$

The exact mechanisms underlying tau toxicity remain a matter of debate. However, recent experiments demonstrated that abnormal activation of kinase-based pathways and disruption of fast axonal transport (FAT) represent toxic gains of function associated with aggregated but not soluble tau species. ${ }^{13-15}$ Specifically, experiments in isolated squid axoplasm revealed that aggregated tau activates a protein phosphatase 1 (PP1) and glycogen synthase kinase 3 (GSK3)-dependent signaling pathway that results in the inhibition of conventional kinesin-dependent anterograde FAT. ${ }^{13}$ Given that aggregated tau pathology is a common denominator in several neurodegenerative diseases and that tau aggregates are demonstrably toxic, it follows that prevention of tau aggregation represents a reasonable therapeutic objective.

Molecular chaperones make up a highly conserved family of related proteins that prevent protein misfolding and aggregation. Chaperone involvement has been implicated in several neurodegenerative diseases, including Parkinson's disease, Huntington's disease, and AD. ${ }^{16-20}$ In particular, molecular chaperones of the Hsp70 family are upregulated in AD and attenuate toxicity in a variety of neurodegenerative disease models. ${ }^{21} \mathrm{Hsp} 70$ has been found to facilitate microtubule binding of tau and is associated with decreased levels of insoluble tau. ${ }^{22,23}$ In addition, Hsp70 facilitates the degradation of insoluble tau aggregates via a direct interaction with CHIP (carboxyl terminus of the Hsc70-interacting protein), a ubiquitin ligase, ${ }^{23}$ or BAG2 (BCL2-associated athanogene 2), a cochaperone. ${ }^{24}$ Taken together, the available data suggest that Hsp70 attenuates tau toxicity by maintaining tau in a 
soluble, nonaggregated state and by facilitating the degradation of aggregated tau species. However, the exact tau aggregate species targeted by Hsp70 chaperones remains unknown. Moreover, specific cellular processes protected by Hsp70 chaperones have not been identified, and thus data showing reduction of tau toxicity remain largely correlative.

In this study, we demonstrate that Hsp70 directly inhibits tau aggregation by a mechanism involving preferential associations with soluble, monomeric and prefibrillar oligomeric tau species. In addition, Hsp70 prevents the toxic effect of preformed tau aggregates on anterograde FAT. When added to preformed tau aggregates in vitro, Hsp70 did not appreciably dissociate tau filaments. Interestingly, Hsp70 was found to associate preferentially with oligomeric versus fibrillar tau aggregates, suggesting that oligomeric aggregates may represent the main toxic species associated with aggregated tau.

\section{EXPERIMENTAL PROCEDURES}

\section{Recombinant Protein Expression and Purification}

hTau40, the longest isoform of tau, consists of 441 amino acids and contains both alternatively spliced $\mathrm{N}$-terminal exons and four microtubule binding repeats (MTBRs). This is the isoform of tau utilized unless otherwise indicated. hTau23, the shortest canonical isoform of tau lacking the alternatively spliced $\mathrm{N}$-terminal exons and the second MTBR, was used when specified. Tau was expressed in Escherichia coli and purified by means of a polyhistidine tag followed by size exclusion chromatography as previously described. ${ }^{25,26}$

\section{Mass Spectrometry}

Recombinant tau preparations were separated by sodium dodecyl sulfate-polyacrylamide gel electrophoresis (SDS-PAGE) using 4 to $15 \%$ linear gradient polyacrylamide gels and stained with Coomassie Blue R-250. Bands of interest were excised, and proteins were digested in situ with trypsin (Promega Corp.). High-performance liquid chromatographyelectrospray tandem mass spectrometry (HPLC-ESI-MS/MS) analyses of the digests were performed on a Thermo Fisher LTQ instrument fitted with a New Objective PicoView 550 nanospray interface. Online HPLC separation of the digests was accomplished with an Eksigent NanoLC micro HPLC system. Mascot (Matrix Science) was used to search the uninterpreted CID spectra against the NCBInr protein database. Methionine was considered as a variable modification. Determination of probabilities of protein identifications and cross correlation of the Mascot results with X! Tandem were accomplished with Scaffold (Proteome Software).

\section{Removal of DnaK}

DnaK was removed from our recombinant tau protein preparations using ion exchange chromatography with HiTrap Q cartridges (GE Life Sciences). Protein was loaded onto the column in $100 \mathrm{mM}$ Tris ( $\mathrm{pH}$ 7.4). Elution was performed using a 20 column volume gradient from 0 to $500 \mathrm{mM} \mathrm{NaCl}$.

\section{Hsp70 Binding Assay}

His-tagged recombinant hTau40 $(4 \mu \mathrm{M})$ was incubated with $2 \mu \mathrm{M}$ Hsp70 (Assay Designs) in $100 \mathrm{mM}$ Tris ( $\mathrm{pH} \mathrm{7.4)}$ ) for $1 \mathrm{~h}$ at ambient temperature. TALON metal affinity resin (Clontech; $2 \mu \mathrm{L}$ ) in binding buffer [final buffer concentrations of $80 \mathrm{mM}$ Tris (pH 7.5), 450 $\mathrm{mM} \mathrm{NaCl}, 4.5 \mathrm{mM}$ imidazole, and $10 \%$ glycerol] was added and incubated for $4 \mathrm{~h}$ with rotation at $4{ }^{\circ} \mathrm{C}$. Samples were centrifuged at $800 \mathrm{~g}$ for $10 \mathrm{~min}$ at $4{ }^{\circ} \mathrm{C}$, and the supernatant was removed. The resin was subjected to five 10 min washes with $10 \mathrm{mM}$ Tris (pH 8.0), 500 $\mathrm{mM} \mathrm{NaCl}, 5 \mathrm{mM}$ imidazole, $10 \%$ glycerol, and $0.1 \%$ Triton X-100 with rotation prior to collection by centrifugation. The final pellet containing resin and bound protein was placed 
in Laemmli sample buffer in a boiling water bath for $5 \mathrm{~min}$ and centrifuged at $16000 \mathrm{~g}$ for 1 min, and the supernatant was collected.

\section{In Vitro Polymerization}

hTau40 $(2 \mu \mathrm{M})$ was incubated at room temperature in aggregation buffer [100 mM Tris, 0.1 mM EGTA, and 5 mM DTT (pH 7.4)] unless otherwise indicated. Recombinant DnaK (Assay Designs; SPP-630) or Hsp70 (Assay Designs; NSP-555) was added to the polymerization reaction mixtures at the indicated concentrations prior to the addition of AA. Tau aggregation was induced using $75 \mu \mathrm{M}$ peroxidase-free arachidonic acid (AA) (Cayman Chemical). Polymerization was monitored by measuring the intensity of right angle laser light scattering as described previously. ${ }^{27}$ Light scattering data from at least three independent experiments were analyzed. Time course data were fit with curves using a onephase exponential association nonlinear regression analysis in GraphPad Prism version 5.0 (GraphPad Software):

$$
Y=Y_{\max }\left(1-\mathbf{e}^{-K X}\right)
$$

where the value of $Y$ ascends from zero to $Y_{\max }$ with a rate constant $K$ and $X$ is the time. The $t_{1 / 2}$ is $0.69 \mathrm{~K}^{-1}$. $\mathrm{IC}_{50}$ values were derived by fitting end point $(t=300 \mathrm{~min})$ light scatter data with one-phase exponential decay nonlinear regression analysis (GraphPad Prism 5.0):

$$
Y=\left(Y_{\max }-Y_{\min }\right) \mathrm{e}^{-K X}+Y_{\min }
$$

where the amount of polymer decreases from $Y_{\max }$ to $Y_{\min }$ with a rate constant $K$.

\section{Tau Aggregate-Hsp70 Sedimentation Assay}

Tau aggregation reaction mixtures containing various concentrations of Hsp70 were incubated for $5 \mathrm{~h}$ in the presence of AA. Each sample was sedimented at $270000 \mathrm{~g}$ and $25^{\circ} \mathrm{C}$ for $30 \mathrm{~min}$ to separate aggregates from monomers. To minimize sample loss, the centrifuge tubes were blocked with bovine serum albumin (BSA) (Thermo Pierce; $2 \mathrm{mg} / \mathrm{mL}$ ) for 10 min and rinsed with $\mathrm{H}_{2} \mathrm{O}$ prior to the addition of the aggregation reaction mixtures.

\section{Immunoblots}

Recombinant protein samples were separated by SDS-PAGE on 4 to $15 \%$ linear gradient gels and transferred to nitrocellulose membranes as described previously. ${ }^{28}$ Samples were probed with polyclonal tau antibody R1 $(0.0025 \mu \mathrm{g} / \mathrm{mL}),{ }^{29}$ an $\mathrm{Hsp} 70$ antibody (Stressmarq; clone C92; $0.2 \mu \mathrm{g} / \mathrm{mL}$ ), or a DnaK antibody (AbCam; clone 8E2/2; $0.025 \mu \mathrm{g} / \mathrm{mL}$ ). DnaK immunoreactivity was quantified using the histogram function of Adobe Photoshop 7.0, using recombinant DnaK (Assay Designs) to make a standard curve.

\section{Electron Microscopy}

For immunogold labeling and quantitative analyses, aggregated samples were diluted 1:10 in $50 \mathrm{mM}$ HEPES and $50 \mathrm{mM} \mathrm{KCl}(\mathrm{pH} 7.6)$ to reduce aggregate clumping. Aggregated tau samples were placed on 300 mesh Formvar/carbon-coated copper or nickel grids [Electron Microscopy Sciences (EMS)], and the grids were exposed briefly to $10 \%$ glutaraldehyde (EMS) prior to being rinsed and stained with $2 \%$ uranyl actetate (EMS). For immunogold labeling, grids were blocked with a $0.1 \%$ gelatin $/ 5 \%$ goat serum (GS) mixture in TBS and incubated with an anti-Hsp70 (Stressmarq; $50 \mu \mathrm{g} / \mathrm{mL}$ ) and/or a His probe (Santa Cruz; 10 $\mu \mathrm{g} / \mathrm{mL}$ ) primary antibody. Grids were then rinsed with TBS prior to incubation with $10 \mathrm{~nm}$ 
(Sigma) or $6 \mathrm{~nm}$ (Jackson ImmunoResearch) diameter gold-conjugated anti-mouse IgG and/ or $10 \mathrm{~nm}$ gold-conjugated anti-rabbit IgG (Sigma) secondary antibodies diluted 1:20 in a 5\% GS/TBS mixture. Finally, grids were rinsed with 10× TBS to reduce the level of nonspecific labeling and rinsed with $\mathrm{H}_{2} \mathrm{O}$ prior to being stained with uranyl acetate.

For quantitative analysis, Optimas 6.0 (Media Cybernetics) was used to measure aggregates (defined as objects $>20 \mathrm{~nm}$ in length). A minimum of five fields per grid were analyzed. To quantify Hsp70 immunogold labeling, aggregated structures were first divided into one of two groups, those $\leq 100 \mathrm{~nm}$ in length and those $>100 \mathrm{~nm}$ in length. This cutoff was chosen because most of the amorphous aggregates were $<100 \mathrm{~nm}$ in size, whereas the majority of the mature tau filaments were $>100 \mathrm{~nm}$ in size (data not shown). Gold labeling for each group is represented as the number of gold particles that label aggregates in a given group divided by the total number of aggregates in that group. Results were normalized to the total number of gold particles per field and multiplied by 100 . Gold particles that label $<20 \mathrm{~nm}$ aggregates were excluded from the analysis.

\section{Squid Axoplasm Motility Assays}

Axoplasm from squid giant axons (Loligo pealii; Marine Biological Laboratory) was extruded as previously described. ${ }^{30}$ For these assays, hTau $40(4 \mu \mathrm{M})$ was polymerized in 50 $\mathrm{mM}$ HEPES, $50 \mathrm{mM} \mathrm{KCl}$, and $5 \mathrm{mM}$ DTT (pH 7.6) using $75 \mu \mathrm{M}$ AA as an inducer. Hsp70 (Assay Designs) was diluted in $50 \mathrm{mM}$ HEPES and $50 \mathrm{mM} \mathrm{KCl}(\mathrm{pH}$ 7.6). Preaggregated hTau40 reaction mixtures or PAD peptide (Genscript) ${ }^{15}$ with or without Hsp70 (final concentration of $1.6 \mu \mathrm{M}$ ) was diluted $1: 1$ in $\mathrm{X} / 2$ buffer [175 mM potassium aspartate, 65 $\mathrm{mM}$ taurine, $35 \mathrm{mM}$ betaine, $25 \mathrm{mM}$ glycine, $10 \mathrm{mM}$ HEPES, $6.5 \mathrm{mM} \mathrm{MgCl}_{2}, 5 \mathrm{mM}$ EGTA, $1.5 \mathrm{mM} \mathrm{CaCl}_{2}$, and $0.5 \mathrm{mM}$ glucose (pH 7.2)] supplemented with $5 \mathrm{mM}$ ATP. Motility was analyzed using a Zeiss Axiomat microscope equipped with a 100×, 1.3 N.A. objective and DIC optics. Organelle velocities were measured by matching calibrated cursor movements to the speed of vesicles moving in the axoplasm. ${ }^{31}$

\section{Statistics}

Sigmastat (Systat Software, Inc.) was used for all statistical tests. Comparisons were made using a paired $t$ test, an unpaired $t$ test, or one-way ANOVA followed by Student-NewmanKeuls post hoc analysis. Data were expressed as means \pm the standard error of the mean (SEM), and significance was set as noted. Comparison of transport data from axoplasms under different conditions was performed using data collected from 40 to 50 min after perfusion.

\section{RESULTS}

\section{Recombinant Tau Protein Directly Interacts with DnaK, a Chaperone of the Hsp70 Family}

When preparations of recombinant tau purified from E. coli by means of a 6x-histidine (His) tag were analyzed by SDS-PAGE, the presence of varying amounts of an $\sim 70 \mathrm{kDa}$ polypeptide was consistently evident (Figure 1A of the Supporting Information). The 70 $\mathrm{kDa}$ protein band was subjected to tryptic digestion, and the peptides obtained were analyzed via HPLC-ESI-MS/MS. Sequence homology analysis of the vast majority of peptides obtained revealed the $70 \mathrm{kDa}$ band corresponded to DnaK, a bacterial member of the Hsp70 family of molecular chaperones.

To determine whether DnaK is universally present in recombinant tau purified from E. coli, several preparations were tested for DnaK immunoreactivity. DnaK was present in all preparations of the longest isoform of tau (hTau40) analyzed, as well as in a preparation of the shortest tau isoform (hTau23), albeit to varying degrees (Figure 1B of the Supporting 
Information). Quantitative immunoblotting analysis indicated that DnaK accounted for approximately $10.5 \pm 0.7 \%$ (mean \pm standard error) of a given recombinant hTau 40 preparation. To determine how Hsp70 family members affect tau aggregation in vitro, we generated an uncontaminated preparation of recombinant tau. We accomplished this by performing ion exchange chromatography to purify monomeric tau from that complexed with DnaK (Figure 1C of the Supporting Information). This purified, DnaK-free tau was used for all studies unless otherwise specified.

To determine whether DnaK affects tau aggregation, hTau40 $(2 \mu \mathrm{M})$ was incubated in the presence of increasing concentrations of recombinant DnaK (Figure 1D of the Supporting Information). Tau aggregation was induced by the addition of AA and monitored using right angle laser light scattering (LLS). A dose-dependent decrease in LLS was observed with increasing concentrations of DnaK, indicative of a reduced level of formation of tau aggregate. On the basis of the range of DnaK contamination observed in our recombinant tau preparations, the amount of inhibition expected in a typical tau aggregation reaction could be estimated. In an aggregation reaction mixture containing $2 \mu \mathrm{M}$ hTau40, the concentration of DnaK ranges from 0.10 to $0.26 \mu \mathrm{M}$ (Figure 3B), corresponding to 19 to $42 \%$ inhibition of tau aggregation, respectively, as estimated from the LLS experiments. These results likely explain the variability we observe in the assembly properties from different tau preparations (data not shown) and stress the importance of removing this chaperone prior to in vitro aggregation experiments.

\section{Hsp70 Inhibits Tau Aggregation in Vitro}

We next sought to determine whether human Hsp70 (HSPA1A), a chaperone with a sequence $50 \%$ homologous to that of DnaK, similarly interacts with tau to inhibit aggregation. A His tag-based pull-down assay was used to evaluate direct protein-protein interactions between purified recombinant hTau 40 and Hsp70. His-tagged recombinant tau was incubated with untagged Hsp70, and the resultant mixture was incubated with TALON metal affinity resin, which avidly binds to the His tag on tau. After extensive washing, an imidazole elution was performed. Hsp70 did not bind to TALON resin in the absence of tau, demonstrating that Hsp70 does not bind the TALON resin nonspecifically. However, when His-tagged tau is added to the reaction mixture, Hsp70 is detected in the elution fraction (Figure 1A). These data indicate that members of the Hsp70 family of chaperones directly bind to soluble monomeric tau, likely because it is a largely unstructured protein. ${ }^{2}$

To evaluate whether direct interaction of tau with Hsp70 influences tau aggregation, purified recombinant hTau $40(2 \mu \mathrm{M})$ was incubated in the presence of varying concentrations of recombinant Hsp70, ranging from 15.6 to $500 \mathrm{nM}$. A dose-dependent reduction in the level of tau aggregation was observed with increasing Hsp70 concentrations (Figure 1B). The $\mathrm{IC}_{50}$ for $\mathrm{Hsp} 70$ was calculated to be $76 \mathrm{nM}$, which corresponds to a stoichiometry of one Hsp70 for every 26 tau macromolecules. ${ }^{a}$ If the primary mechanism of Hsp70 inhibition consisted of removing monomeric tau from the aggregation reaction mixture, then $96 \%$ of the total tau $(>1.9 \mu \mathrm{M})$ would still be able to aggregate. Therefore, this substoichiometric inhibition suggests that Hsp70 may interact with tau aggregates, thus inhibiting further assembly. Moreover, Hsp70 affects the extent $\left(Y_{\max }\right)$ but not the rate $(K)$ of polymerization (Table 1). This supports a model in which Hsp70 does not appreciably affect nucleation but prevents additional tau monomers from being incorporated into existing tau aggregates.

As an independent experimental approach, transmission electron microscopy (EM) was used to verify results from LLS experiments. These experiments confirmed that incubation of tau with Hsp70 resulted in a dose-dependent reduction in the overall amount of aggregated material observed per field (Figure 1C). Qualitative analysis revealed that filament length decreased with an increasing Hsp70 concentration. Moreover, at the highest concentration of 
Hsp70 tested (Hsp70:tau molar ratio of 1:4), filaments were rarely observed while only small predominantly oligomeric aggregates remained. Hence, Hsp70, though a potent inhibitor of tau filament formation, appears to be somewhat less effective at inhibiting the formation of tau oligomers.

To ensure that the oligomeric aggregates observed by EM do not result from Hsp70 aggregation, we co-incubated Hsp70 $(2 \mu \mathrm{M})$ with AA, using an equimolar concentration of BSA as an alternative substrate. Hsp70 has been reported to bind albumin with a $K_{\mathrm{d}}$ on the same order of magnitude as that of tau, and it has already been documented that Hsp70 will self-associate if no substrate is present. ${ }^{32-34}$ No aggregates were observed by EM, indicating that Hsp70 is not aggregating under our experimental conditions. Taken together, these results demonstrate that $\mathrm{Hsp} 70$ directly and potently inhibits tau aggregation in vitro.

As previously reported for Hsp70 inhibition of a-synuclein aggregation, ${ }^{35-37}$ the inhibition of tau aggregation promoted by Hsp70 did not require ATP or cochaperones (e.g., Hsp40) as the experiments presented here were performed in their absence. In fact, the addition of ATP to the reaction mixture did not significantly affect our findings (data not shown).

\section{Hsp70 Preferentially Associates with Tau Oligomers}

The experiments described above demonstrated that Hsp70 directly interacts with soluble tau. However, because Hsp70 hinders tau aggregation at substoichiometric concentrations, it follows that Hsp70 may also interact with small oligomeric and/or filamentous tau aggregates, thereby preventing the further addition of monomeric tau to these aggregates. To determine whether Hsp70 interacts with tau aggregates, Hsp70/tau mixtures were sedimented after the addition of AA or ethanol vehicle (Figure 2A). As predicted, both Hsp70 and tau are found in the supernatant in the absence of AA. However, when AA is added to the reaction mixture, Hsp70 sediments with tau, indicating Hsp70 binds to some form of tau aggregate. Moreover, it was previously demonstrated that AA does not sediment with tau aggregates, ${ }^{38}$ signifying that $\mathrm{Hsp} 70$ does not interact with AA. Immunogold labeling of Hsp70 was utilized to confirm that Hsp70 appears to associate with tau aggregates that sediment (Figure 2A).

We have demonstrated that Hsp70 binds tau when added prior to the initiation of aggregation. We next sought to determine whether Hsp70 preferentially associated with preformed filamentous and/or oligomeric tau aggregates, as tau assembled in vitro is composed of a mixture of both. Purified hTau $40(2 \mu \mathrm{M})$ was incubated with AA and aggregated in the absence of $\mathrm{Hsp} 70$. Once the reaction reached equilibrium $(5 \mathrm{~h})$, an equimolar concentration of Hsp70 was added. Immunogold labeling of these tau aggregate/ Hsp70 mixtures with an anti-Hsp70 antibody revealed that the vast majority of Hsp70 associates with amorphous oligomeric aggregates, and only occasional labeling was found on filaments (Figure 2B). In fact, Hsp70 was 3 times more likely to associate with small oligomeric aggregates ( $₫ 00 \mathrm{~nm}$ ) than filamentous ones (>100 nm) (Figure 2C). Even so, this is still an overestimation of filament labeling as larger filamentous aggregates possess far more individual tau proteins with which $\mathrm{Hsp} 70$ could potentially interact compared to oligomeric aggregates. Finally, we verified that these aggregates possess both Hsp70 and tau using double-label immunogold EM analysis. Amorphous tau aggregates were doubly labeled with anti-Hsp70 and anti-His antibodies, confirming that Hsp70 preferentially associates with oligomeric tau aggregates and only occasionally with filamentous aggregates (Figure 2D). From these data, we concluded that Hsp70 not only prevents tau aggregation but also binds to preexisting oligomeric tau aggregates.

Though the majority of Hsp70 macromolecules associated with oligomeric aggregates, some filament labeling was observed. Recent evidence casts doubt on the toxicity of fibrillar tau 
aggregates, suggesting instead that tau oligomers may represent the main neurotoxic species (reviewed in ref 7). Should Hsp70 promote dissociation of tau filaments into smaller oligomeric aggregates, this effect could be detrimental to neurons. Thus, we set out to determine the effect of Hsp70 on preexisting tau filaments. Tau $(2 \mu \mathrm{M})$ was aggregated for 5 $\mathrm{h}$ prior to the addition of an equimolar concentration of Hsp70. After incubation for $24 \mathrm{~h}$, quantitative EM was performed (Figure 3A,B). No significant difference in the overall mass, number, or length of tau aggregates was observed (Figure 3C,D). The only detectable effects were a small but statistically significant decrease in the number of $>200 \mathrm{~nm}$ tau aggregates. From these data, we concluded that Hsp70 may have, at most, a mild dissociative effect on a subset of preformed aggregates.

\section{Hsp70 Abolishes the Effects of Tau Aggregates on Fast Axonal Transport}

The data described above demonstrated that Hsp70 avidly binds to oligomeric and, to a lesser extent, filamentous tau aggregates. On the basis of these data, we evaluated whether Hsp70 alters the toxic properties of tau aggregates. Our recent work using isolated squid axoplasm demonstrated that tau aggregates, but not soluble tau monomers, selectively inhibited anterograde, conventional kinesin-dependent fast axonal transport (FAT), leaving retrograde, cytoplasmic dynein-dependent FAT unaffected. ${ }^{13}$ This toxic effect of aggregated tau on anterograde FAT results from abnormal activation of a PP1-GSK3 signal transduction pathway that culminates in the phosphorylation of kinesin light chains by GSK3, and the release of conventional kinesin from its transported cargoes. ${ }^{13,15}$ Interestingly, these aggregated tau reaction mixtures contain both oligomeric and filamentous aggregates. Whether oligomer, filaments, or perhaps both forms of tau aggregates are toxic remains to be determined.

Vesicle motility assays in isolated axoplasm were used to determine whether Hsp70 impacts the toxicity of tau aggregates on FAT. Hsp70 was incubated with tau aggregates prior to their addition to the axoplasm, thus allowing Hsp70-tau interactions prior to perfusion. As previously shown, soluble tau did not affect FAT (Figure 4A), whereas aggregated tau selectively inhibited anterograde FAT (Figure 4B). ${ }^{13,15}$ Remarkably, preincubation of Hsp70 with tau aggregates completely prevented their inhibitory effect on anterograde FAT (Figure 4C). Additionally, we endeavored to ascertain the effect of Hsp70 alone on axonal transport. Hsp70 by itself had a mild depressive effect on both anterograde and retrograde transport (Figure 5A), likely because it is a chaperone that is known to interact with numerous proteins. Even so, this effect was not observed in the presence of tau aggregates (Figure 4C), suggesting that Hsp70 is indeed binding tau aggregates very tightly to prevent their effects on FAT.

As an additional control, we co-incubated Hsp70 with the phosphatase activating domain (PAD) peptide (amino acids 2-18 of hTau40). ${ }^{13,15}$ When tau aggregates, it is the exposure of the PAD domain that activates the PP1-GSK3 signaling cascade, resulting in anterograde FAT inhibition (Figure 5B). ${ }^{13,15}$ Because PAD alone is capable of inhibiting anterograde axoplasmic transport ${ }^{15}$ and $\mathrm{Hsp} 70$ interacts with hydrophobic substrates such as the VQIVYK and VQIINK hexapeptide motifs in the MTBR region of tau, ${ }^{32}$ we hypothesized that Hsp70 would not prevent the toxic effect of PAD on transport. In fact, this was exactly what we observed. PAD in the presence of Hsp70 still inhibited anterograde FAT beyond the mild inhibition observed with Hsp70 alone, whereas no additional effect was observed on retrograde FAT (Figure 5C). Taken together, our results strongly suggest that Hsp70 prevents the toxicity of aggregated tau via a direct interaction with these aggregates. These results, in conjunction with the immunogold studies that demonstrated that Hsp70 preferentially binds to tau oligomers, advocate that it is, in fact, tau oligomers that are responsible for the observed effect on FAT. 


\section{DISCUSSION}

Displacement of tau from microtubules allows for its self-association and deposition. In opposition, molecular chaperones, like the Hsp70 chaperone family, prevent protein aggregation by binding exposed hydrophobic residues. Though the Hsp70 family has several members, the two that are predominantly expressed in the cytoplasm are the constitutively expressed heat shock cognate 70 (Hsc70) and its stress-induced counterpart, Hsp70; their sequences are $92 \%$ homologous (reviewed in ref 39). Co-immunoprecipitation of Hsp70 with tau has been previously reported in various cell lines ${ }^{32,40}$ as well as human brain extracts. ${ }^{41}$ Moreover, it was demonstrated that $\mathrm{Hsc} 70$ rapidly associates with tau after microtubule destabilization. ${ }^{42}$ Here, we report a direct interaction between Hsp70 and soluble tau in vitro and demonstrate that this interaction inhibits the self-association of tau into aggregates. Additionally, we show that Hsp70 also interacts with preexisting tau aggregates, having a preferential selectivity for oligomeric versus filamentous tau aggregates. Finally, our studies indicate that binding of Hsp70 to tau aggregates prevented their toxic effect on FAT. These findings are summarized in Figure 6.

It is highly likely that Hsp70 interacts with tau in a manner similar to that of Hsc70, which appears to bind to two hydrophobic stretches of the tau protein, VQII and VQIV, located in the second and third MTBRs, respectively. ${ }^{32}$ These are the same two motifs discovered to be essential for tau aggregation. ${ }^{43-46}$ However, the reported $K_{\mathrm{D}}$ values for tau-Hsc70 binding are more than 100 -fold lower than those for tau-tau binding, ${ }^{47}$ which strongly suggested that Hsc70 competitively inhibits tau-tau interactions. A previous report indicated that a nearly mutually exclusive relationship existed between tau neurofibrillary pathology and neurons that stain strongly for Hsp70 in AD, suggesting a role for Hsp70 in preventing fibrillar tau agggregation. ${ }^{22}$ Moreover, Hsp70 was shown to reduce the level of tau aggregation in several cell lines ${ }^{22,23}$ and animal models. ${ }^{23,48}$ Our current studies using highly purified components indicate that $\mathrm{Hsp} 70$ inhibits the formation of tau filaments in a dose-dependent fashion. The inhibitory effect of Hsp70 on tau aggregation involved interactions of Hsp70 with both soluble tau monomers and oligomeric tau aggregates. Additionally, our work appears to be consistent with a previous study in which Hsp70 inhibited heparin-induced tau aggregation in vitro as measured by the decreased fluorescence of thioflavin T (ThT), a dye that recognizes the $\beta$-pleated sheet conformation usually associated with fibril formation; however, unlike our results, this decrease was not dose-dependent. ${ }^{41}$ This discrepancy may be explained by the fact that ThT fluorescence is unable to distinguish between different forms of aggregation, i.e., oligomeric and filamentous aggregates. As demonstrated here, even at the highest concentration of Hsp70 tested, oligomeric aggregates persist. The conspicuous absence of tau fibrils at substoichiometric concentrations of Hsp70 suggests that the association of Hsp70 with tau oligomers may sequester tau in stable "off-pathway" aggregates. A similar mechanism has already been proposed for $a$-synuclein, amyloid $\beta$, and huntingtin; ${ }^{49-51}$ however, this is the first mechanistic study describing how Hsp70 inhibits tau polymerization. Further studies are necessary to determine how Hsp70 alters tau's conformation, ultimately resulting in a decreased level of filament formation.

Our data indicate that Hsp70 alone has little depolymerizing effect on preexisting tau filaments. Highly ordered amyloid fibrils are very stable, and the hydrophobic binding sites necessary for Hsp70 interaction are likely buried within the fibril. Though very efficient at preventing the conformational state that results in fibril formation, Hsp70 alone cannot readily reverse this conformational shift once it has occurred. However, in vivo, cochaperones, including Hsp40 and Hsp90, augment Hsp70 activity. ${ }^{52}$ Thus, it is conceivable that Hsp70 in combination with other cochaperones may be capable of rearranging tau filaments. In this regard, our data agree with previously reported studies indicating that $\mathrm{Hsp} 70$ alone cannot rearrange mature $\mathrm{A} \beta$, huntingtin, or $\alpha$-synuclein 
fibrils. ${ }^{35,49,51}$ On the other hand, we demonstrate that Hsp70 preferentially interacts with oligomeric tau aggregates. This suggests that the hydrophobic binding sites for Hsp70 on tau are more readily available in tau oligomers than in tau filaments. Thus, the MTBR domains, which form the core of the NFT, are likely more exposed in the oligomer.

Though Hsp70 does not appear to influence the morphology of preformed tau aggregates, we found that it does attenuate the toxicity of these aggregates. Using vesicle motility assays in isolated axoplasm, we previously reported that a mixture of oligomeric and filamentous tau aggregates selectively impaired anterograde FAT. This toxic effect of tau aggregates was mediated by PP1 and GSK $3^{13}$ and involved an increased level of exposure of a phosphatase activation domain (PAD), a 17-amino acid sequence located in the amino terminus of tau. ${ }^{15}$ Interestingly, we found that Hsp70 completely reverses this effect and that this reversal appears to be mediated by a direct interaction of Hsp70 with aggregated tau. Given that immunogold labeling of Hsp70 revealed limited labeling of filaments and abundant labeling of small oligomeric structures, it is likely that tau oligomers are the main species responsible for inhibition of anterograde FAT, supporting the hypothesis that prefibrillar oligomeric tau species are more toxic than mature fibrils. ${ }^{7}$ Furthermore, Hsp70 did not alter the inhibitory effect of PAD peptide on anterograde FAT, indicating that Hsp70 is not interacting with PAD, directly leaving us to speculate that the protective effect of Hsp70 on FAT likely involves a reduction in PAD availability. Obtaining adequate support for this contention, however, will require further experimentation.

\section{Supplementary Material}

Refer to Web version on PubMed Central for supplementary material.

\section{Acknowledgments}

We thank Dr. Susan Weintraub and Kevin Hakala for the mass spectrometry work as well as Dr. Yuyu Song for her contribution to the squid axoplasm motility assays.

Funding This work was supported by National Institutes of Health Grants T32 AF020506 (K.R.P.), AG09466 and AG032091 (L.I.B.), and NS23868 and NS23320 (S.T.B.).

\section{ABBREVIATIONS}

AA arachidonic acid;

AD Alzheimer's disease;

FAT fast axoplasmic transport;

GSK3 glycogen synthase kinase 3;

Hsp70 heat shock protein 70;

LLS laser light scattering;

NFT neurofibrillary tangle;

PP1 protein phosphatase 1.

\section{REFERENCES}

(1). Amos LA, Schlieper D. Microtubules and maps. Adv. Protein Chem. 2005; 71:257-298. [PubMed: 16230114] 
(2). Schweers O, Schonbrunn-Hanebeck E, Marx A, Mandelkow E. Structural studies of tau protein and Alzheimer paired helical filaments show no evidence for $\beta$-structure. J. Biol. Chem. 1994; 269:24290-24297. [PubMed: 7929085]

(3). Iqbal K, Liu F, Gong CX, Alonso Adel C, Grundke-Iqbal I. Mechanisms of tau-induced neurodegeneration. Acta Neuropathol. 2009; 118:53-69. [PubMed: 19184068]

(4). Patterson KR, Remmers C, Fu Y, Brooker S, Kanaan NM, Vana L, Ward S, Reyes JF, Philibert K, Glucksman MJ, Binder LI. Characterization of prefibrillar tau oligomers in vitro and in Alzheimers disease. J. Biol. Chem. 2011; 286:23063-23076. [PubMed: 21550980]

(5). Feany MB, Dickson DW. Neurodegenerative disorders with extensive tau pathology: A comparative study and review. Ann. Neurol. 1996; 40:139-148. [PubMed: 8773594]

(6). Arriagada PV, Growdon JH, Hedley-Whyte ET, Hyman BT. Neurofibrillary tangles but not senile plaques parallel duration and severity of Alzheimer's disease. Neurology. 1992; 42:631-639. [PubMed: 1549228]

(7). Ding H, Johnson GV. The last tangle of tau. J. Alzheimer's Dis. 2008; 14:441-447. [PubMed: 18688096]

(8). Wittmann CW, Wszolek MF, Shulman JM, Salvaterra PM, Lewis J, Hutton M, Feany MB. Tauopathy in Drosophila: Neurodegeneration without neurofibrillary tangles. Science. 2001; 293:711-714. [PubMed: 11408621]

(9). Andorfer C, Acker CM, Kress Y, Hof PR, Duff K, Davies P. Cell-cycle reentry and cell death in transgenic mice expressing nonmutant human tau isoforms. J. Neurosci. 2005; 25:5446-5454. [PubMed: 15930395]

(10). Berger Z, Roder H, Hanna A, Carlson A, Rangachari V, Yue M, Wszolek Z, Ashe K, Knight J, Dickson D, Andorfer C, Rosenberry TL, Lewis J, Hutton M, Janus C. Accumulation of pathological tau species and memory loss in a conditional model of tauopathy. J. Neurosci. 2007; 27:3650-3662. [PubMed: 17409229]

(11). Santacruz K, Lewis J, Spires T, Paulson J, Kotilinek L, Ingelsson M, Guimaraes A, DeTure M, Ramsden M, McGowan E, Forster C, Yue M, Orne J, Janus C, Mariash A, Kuskowski M, Hyman B, Hutton M, Ashe KH. Tau suppression in a neurodegenerative mouse model improves memory function. Science. 2005; 309:476-481. [PubMed: 16020737]

(12). Sydow A, Van der Jeugd A, Zheng F, Ahmed T, Balschun D, Petrova O, Drexler D, Zhou L, Rune G, Mandelkow E, D'Hooge R, Alzheimer C, Mandelkow EM. Tau-induced defects in synaptic plasticity, learning, and memory are reversible in transgenic mice after switching off the toxic tau mutant. J. Neurosci. 2011; 31:2511-2525. [PubMed: 21325519]

(13). LaPointe NE, Morfini G, Pigino G, Gaisina IN, Kozikowski AP, Binder LI, Brady ST. The amino terminus of tau inhibits kinesin-dependent axonal transport: Implications for filament toxicity. J. Neurosci. Res. 2009; 87:440-451. [PubMed: 18798283]

(14). Morfini G, Pigino G, Mizuno N, Kikkawa M, Brady ST. Tau binding to microtubules does not directly affect microtubule-based vesicle motility. J. Neurosci. Res. 2007; 85:2620-2630. [PubMed: 17265463]

(15). Kanaan NM, Morfini GA, LaPointe NE, Pigino GF, Patterson KR, Song Y, Andreadis A, Fu Y, Brady ST, Binder LI. Pathogenic forms of tau inhibit kinesin-dependent axonal transport through a mechanism involving activation of axonal phosphotransferases. J. Neurosci. 2011; 31:98589868. [PubMed: 21734277]

(16). Ostrerova N, Petrucelli L, Farrer M, Mehta N, Choi P, Hardy J, Wolozin B. a-Synuclein shares physical and functional homology with 14-3-3 proteins. J. Neurosci. 1999; 19:5782-5791. [PubMed: 10407019]

(17). Carmichael J, Chatellier J, Woolfson A, Milstein C, Fersht AR, Rubinsztein DC. Bacterial and yeast chaperones reduce both aggregate formation and cell death in mammalian cell models of Huntington's disease. Proc. Natl. Acad. Sci. U.S.A. 2000; 97:9701-9705. [PubMed: 10920207]

(18). Warrick JM, Chan HY, Gray-Board GL, Chai Y, Paulson HL, Bonini NM. Suppression of polyglutamine-mediated neurodegeneration in Drosophila by the molecular chaperone HSP70. Nat. Genet. 1999; 23:425-428. [PubMed: 10581028]

(19). Sittler A, Lurz R, Lueder G, Priller J, Lehrach H, Hayer-Hartl MK, Hartl FU, Wanker EE. Geldanamycin activates a heat shock response and inhibits huntingtin aggregation in a cell 
culture model of Huntington's disease. Hum. Mol. Genet. 2001; 10:1307-1315. [PubMed: 11406612]

(20). Smith RC, Rosen KM, Pola R, Magrane J. Stress proteins in Alzheimer's disease. Int. J. Hyperthermia. 2005; 21:421-431. [PubMed: 16048839]

(21). Arawaka S, Machiya Y, Kato T. Heat shock proteins as suppressors of accumulation of toxic prefibrillar intermediates and misfolded proteins in neurodegenerative diseases. Curr. Pharm. Biotechnol. 2010; 11:158-166. [PubMed: 20170473]

(22). Dou F, Netzer WJ, Tanemura K, Li F, Hartl FU, Takashima A, Gouras GK, Greengard P, Xu H. Chaperones increase association of tau protein with microtubules. Proc. Natl. Acad. Sci. U.S.A. 2003; 100:721-726. [PubMed: 12522269]

(23). Petrucelli L, Dickson D, Kehoe K, Taylor J, Snyder H, Grover A, De Lucia M, McGowan E, Lewis J, Prihar G, Kim J, Dillmann WH, Browne SE, Hall A, Voellmy R, Tsuboi Y, Dawson TM, Wolozin B, Hardy J, Hutton M. CHIP and Hsp70 regulate tau ubiquitination, degradation and aggregation. Hum. Mol. Genet. 2004; 13:703-714. [PubMed: 14962978]

(24). Carrettiero DC, Hernandez I, Neveu P, Papagiannakopoulos T, Kosik KS. The cochaperone BAG2 sweeps paired helical filament-insoluble tau from the microtubule. J. Neurosci. 2009; 29:2151-2161. [PubMed: 19228967]

(25). Carmel G, Leichus B, Cheng X, Patterson SD, Mirza U, Chait BT, Kuret J. Expression, purification, crystallization, and preliminary X-ray analysis of casein kinase- 1 from Schizosaccharomyces pombe. J. Biol. Chem. 1994; 269:7304-7309. [PubMed: 8125945]

(26). Abraha A, Ghoshal N, Gamblin TC, Cryns V, Berry RW, Kuret J, Binder LI. C-terminal inhibition of tau assembly in vitro and in Alzheimer's disease. J. Cell Sci. 2000; 113:3737-3745. [PubMed: 11034902]

(27). Gamblin TC, King ME, Dawson H, Vitek MP, Kuret J, Berry RW, Binder LI. In vitro polymerization of tau protein monitored by laser light scattering: Method and application to the study of FTDP-17 mutants. Biochemistry. 2000; 39:6136-6144. [PubMed: 10821687]

(28). Reyes JF, Reynolds MR, Horowitz PM, Fu Y, Guillozet-Bongaarts AL, Berry R, Binder LI. A possible link between astrocyte activation and tau nitration in Alzheimer's disease. Neurobiol. Dis. 2008; 31:198-208. [PubMed: 18562203]

(29). Berry RW, Sweet AP, Clark FA, Lagalwar S, Lapin BR, Wang T, Topgi S, Guillozet-Bongaarts AL, Cochran EJ, Bigio EH, Binder LI. Tau epitope display in progressive supranuclear palsy and corticobasal degeneration. J. Neurocytol. 2004; 33:287-295. [PubMed: 15475684]

(30). Brady ST, Lasek RJ, Allen RD. Video microscopy of fast axonal transport in extruded axoplasm: A new model for study of molecular mechanisms. Cell Motil. 1985; 5:81-101. [PubMed: 2580632]

(31). Morfini G, Pigino G, Szebenyi G, You Y, Pollema S, Brady ST. JNK mediates pathogenic effects of polyglutamine-expanded androgen receptor on fast axonal transport. Nat. Neurosci. 2006; 9:907-916. [PubMed: 16751763]

(32). Sarkar M, Kuret J, Lee G. Two motifs within the tau microtubule-binding domain mediate its association with the hsc70 molecular chaperone. J. Neurosci. Res. 2008; 86:2763-2773. [PubMed: 18500754]

(33). Oddi S, Fezza F, Pasquariello N, D'Agostino A, Catanzaro G, De Simone C, Rapino C, FinazziAgro A, Maccarrone M. Molecular identification of albumin and Hsp70 as cytosolic anandamide-binding proteins. Chem. Biol. 2009; 16:624-632. [PubMed: 19481477]

(34). Benaroudj N, Triniolles F, Ladjimi MM. Effect of nucleotides, peptides, and unfolded proteins on the self-association of the molecular chaperone HSC70. J. Biol. Chem. 1996; 271:18471-18476. [PubMed: 8702492]

(35). Dedmon MM, Christodoulou J, Wilson MR, Dobson CM. Heat shock protein 70 inhibits asynuclein fibril formation via preferential binding to prefibrillar species. J. Biol. Chem. 2005; 280:14733-14740. [PubMed: 15671022]

(36). Huang C, Cheng H, Hao S, Zhou H, Zhang X, Gao J, Sun QH, Hu H, Wang CC. Heat shock protein 70 inhibits a-synuclein fibril formation via interactions with diverse intermediates. J. Mol. Biol. 2006; 364:323-336. [PubMed: 17010992] 
(37). Luk KC, Mills IP, Trojanowski JQ, Lee VM. Interactions between Hsp70 and the hydrophobic core of a-synuclein inhibit fibril assembly. Biochemistry. 2008; 47:12614-12625. [PubMed: 18975920]

(38). Carlson SW, Branden M, Voss K, Sun Q, Rankin CA, Gamblin TC. A complex mechanism for inducer mediated tau polymerization. Biochemistry. 2007; 46:8838-8849. [PubMed: 17608454]

(39). Daugaard M, Rohde M, Jaattela M. The heat shock protein 70 family: Highly homologous proteins with overlapping and distinct functions. FEBS Lett. 2007; 581:3702-3710. [PubMed: 17544402]

(40). Johnson G, Refolo LM, Wallace W. Heatshocked neuronal PC12 cells reveal Alzheimer's disease-associated alterations in amyloid precursor protein and tau. Ann. N.Y. Acad. Sci. 1993; 695:194-197. [PubMed: 8239282]

(41). Sahara N, Maeda S, Yoshiike Y, Mizoroki T, Yamashita S, Murayama M, Park JM, Saito Y, Murayama S, Takashima A. Molecular chaperone-mediated tau protein metabolism counteracts the formation of granular tau oligomers in human brain. J. Neurosci. Res. 2007; 85:3098-3108. [PubMed: 17628496]

(42). Jinwal UK, O'Leary JC III, Borysov SI, Jones JR, Li Q, Koren J III, Abisambra JF, Vestal GD, Lawson LY, Johnson AG, Blair LJ, Jin Y, Miyata Y, Gestwicki JE, Dickey CA. Hsc70 rapidly engages tau after microtubule destabilization. J. Biol. Chem. 2010; 285:16798-16805. [PubMed: 20308058]

(43). Giannetti AM, Lindwall G, Chau MF, Radeke MJ, Feinstein SC, Kohlstaedt LA. Fibers of tau fragments, but not full length tau, exhibit a cross $\beta$-structure: Implications for the formation of paired helical filaments. Protein Sci. 2000; 9:2427-2435. [PubMed: 11206064]

(44). von Bergen M, Friedhoff P, Biernat J, Heberle J, Mandelkow E. Assembly of tau protein into Alzheimer paired helical filaments depends on a local sequence motif (306VQIVYK311) forming $\beta$ structure. Proc. Natl. Acad. Sci. U.S.A. 2000; 97:5129-5134. [PubMed: 10805776]

(45). Li W, Lee VM. Characterization of two VQIXXK motifs for tau fibrillization in vitro. Biochemistry. 2006; 45:15692-15701. [PubMed: 17176091]

(46). Santa-Maria I, Perez M, Hernandez F, Munoz V, Moreno FJ, Avila J. In vitro tau fibrillization: Mapping protein regions. Biochim. Biophys. Acta. 2006; 1762:683-692. [PubMed: 16891100]

(47). Guo JP, Arai T, Miklossy J, McGeer PL. A $\beta$ and tau form soluble complexes that may promote self aggregation of both into the insoluble forms observed in Alzheimer's disease. Proc. Natl. Acad. Sci. U.S.A. 2006; 103:1953-1958. [PubMed: 16446437]

(48). Jinwal UK, Miyata Y, Koren J III, Jones JR, Trotter JH, Chang L, O'Leary J, Morgan D, Lee DC, Shults CL, Rousaki A, Weeber EJ, Zuiderweg ER, Gestwicki JE, Dickey CA. Chemical manipulation of hsp70 ATPase activity regulates tau stability. J. Neurosci. 2009; 29:12079_ 12088. [PubMed: 19793966]

(49). Muchowski PJ, Schaffar G, Sittler A, Wanker EE, Hayer-Hartl MK, Hartl FU. Hsp70 and Hsp40 chaperones can inhibit self-assembly of polyglutamine proteins into amyloid-like fibrils. Proc. Natl. Acad. Sci. U.S.A. 2000; 97:7841-7846. [PubMed: 10859365]

(50). Wacker JL, Zareie MH, Fong H, Sarikaya M, Muchowski PJ. Hsp70 and Hsp40 attenuate formation of spherical and annular polyglutamine oligomers by partitioning monomer. Nat. Struct. Mol. Biol. 2004; 11:1215-1222. [PubMed: 15543156]

(51). Evans CG, Wisen S, Gestwicki JE. Heat shock proteins 70 and 90 inhibit early stages of amyloid $\beta-(1-42)$ aggregation in vitro. J. Biol. Chem. 2006; 281:33182-33191. [PubMed: 16973602]

(52). Langer T, Lu C, Echols H, Flanagan J, Hayer MK, Hartl FU. Successive action of DnaK, DnaJ and GroEL along the pathway of chaperone-mediated protein folding. Nature. 1992; 356:683689. [PubMed: 1349157] 

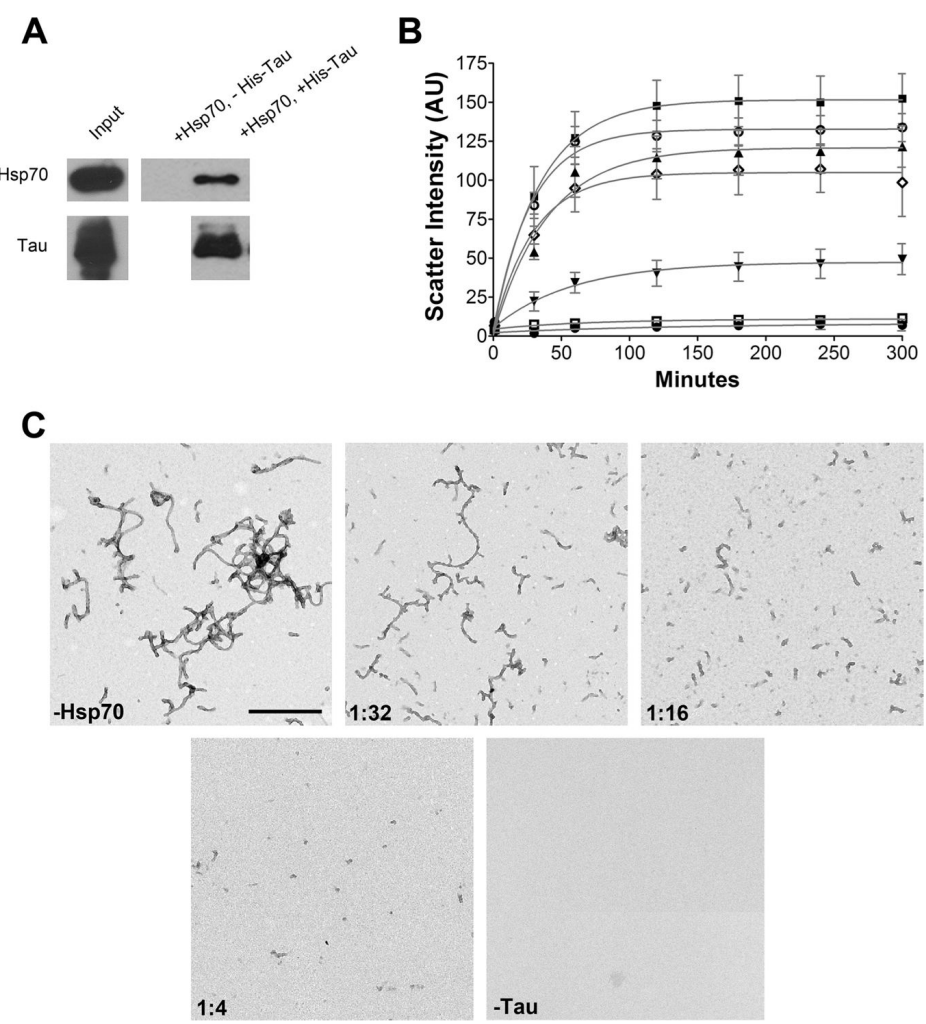

Figure 1.

Hsp70 forms a complex with tau and inhibits aggregation in vitro. (A) His-tagged hTau40 was incubated with untagged Hsp70 (HSPA1A). Reaction mixtures were incubated with TALON metal affinity resin, which interacts with the His tag located on tau. Proteins bound to the resin were immunoblotted for Hsp70 and tau. The Hsp70 alone control confirms that Hsp70 does not bind nonspecifically to the resin. In the presence of tau, Hsp70 is detected in the elution fraction. (B) Intensity of right angle light scattering as a function of time. Each time point is the average of at least three independent experiments and is represented as the mean \pm SEM: $(\mathbf{\square})$ Tau alone $(2 \mu \mathrm{M}),(\bigcirc)$ 1:128 Hsp70:tau ratio, $(\boldsymbol{\Delta})$ 1:64 Hsp70:tau ratio,

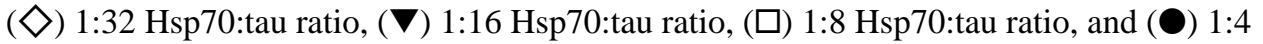
Hsp70:tau ratio. (C) Representative electron micrographs of aggregation reactions at equilibrium ( $t=300 \mathrm{~min}$ ). Note the decreased level of formation of filamentous aggregates while some oligomeric aggregates persist even at the highest concentrations tested. The scale bar is $500 \mathrm{~nm}$. The bottom right image (-Tau) is Hsp70 in aggregation buffer (+AA) in the absence of tau. 
A
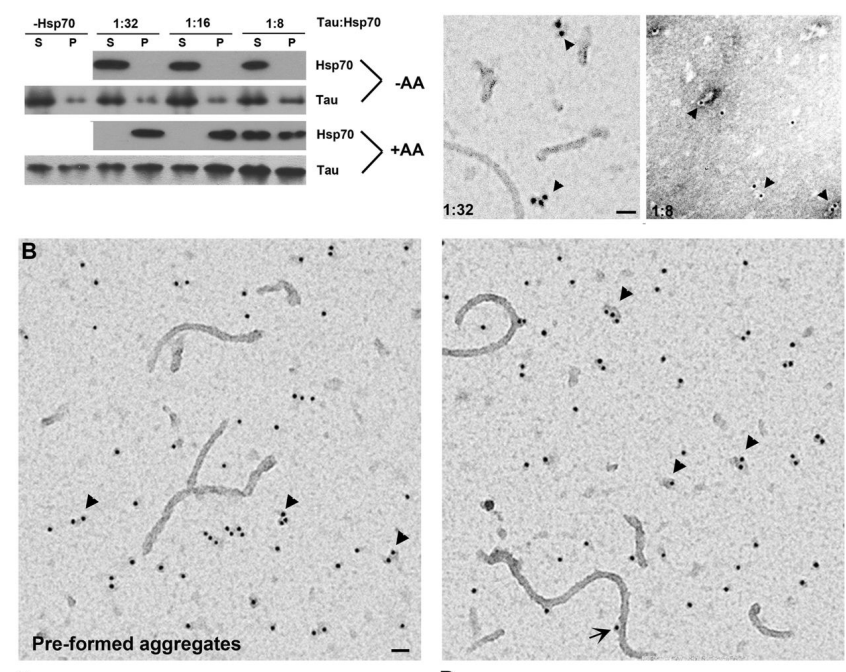

C
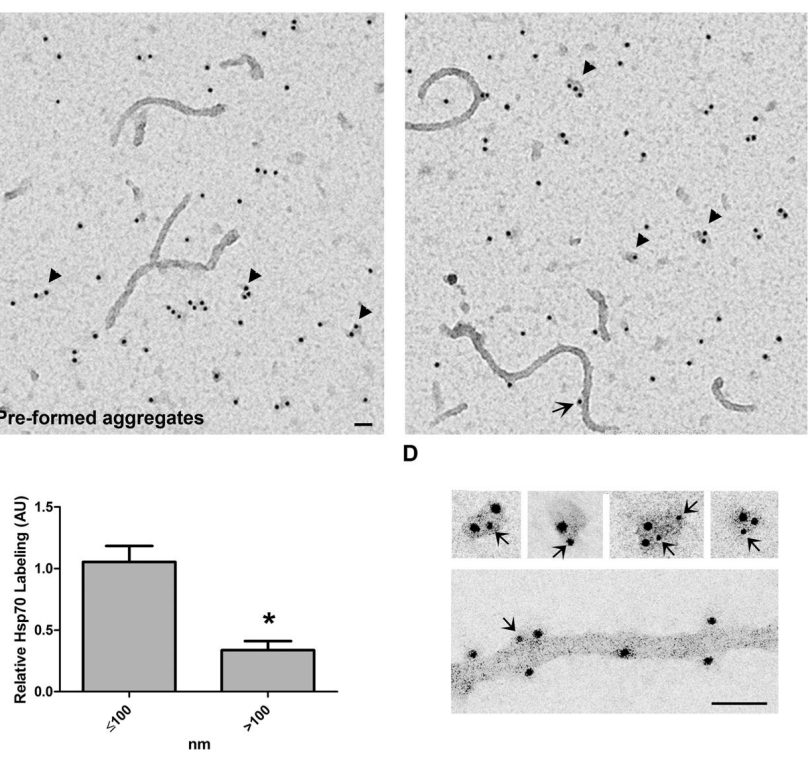

Figure 2.

Hsp70 associates with tau aggregates. (A) Tau was aggregated in the presence of varying concentrations of Hsp70 for $5 \mathrm{~h}$. After centrifugation, the resulting supernatant (S) and pellet (P) fractions were analyzed by immunoblotting using anti-Hsp70 and anti-tau antibodies. In the absence of AA (-AA), both Hsp70 and hTau40 remain in the supernatant fractions. When AA is added (+AA), Hsp70 cosediments with tau in pellet fractions. Electron micrographs demonstrate immunogold labeling of Hsp70 on amorphous tau oligomers. The ratio at the bottom left is the Hsp70:tau ratio. (B) Hsp70 was added to preformed oligomeric and filamentous tau aggregates. Electron micrographs demonstrate abundant Hsp70 immunogold labeling of oligomeric structures (arrowheads) but very limited labeling of tau filaments (arrow). (C) Quantification of Hsp70 immunogold labeling. Hsp70 was 3 times more likely to label $\leq 100 \mathrm{~nm}$ structures than $>100 \mathrm{~nm}$ structures. ${ }^{*} p<0.01$ (Student's $t$ test). (D) Double immunogold labeling of Hsp70 (arrow) and the His tag on tau. Several amorphous aggregates were labeled for both. Also shown is a tau filament that is labeled for Hsp70. Hsp70 is labeled with $6 \mathrm{~nm}$ gold particles. His-tagged hTau40 is labeled with $10 \mathrm{~nm}$ gold particles. The scale bars are $50 \mathrm{~nm}$. 

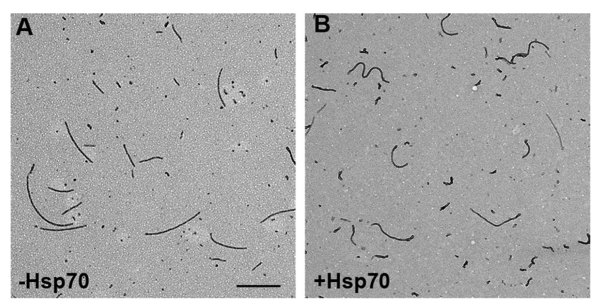

C

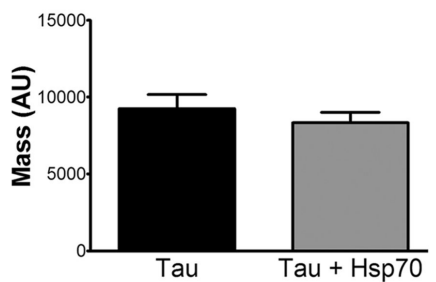

D

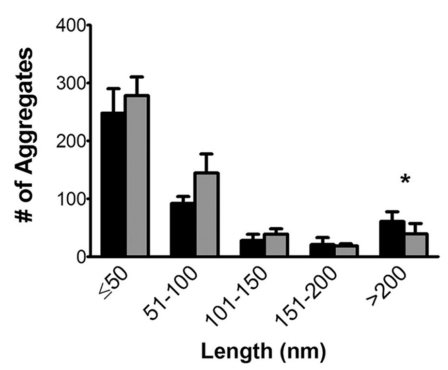

Figure 3.

Hsp70 has a modest effect on mature tau filaments. Electron micrographs of (A) preformed tau aggregates and (B) preformed tau aggregates with Hsp70. The scale bar is $500 \mathrm{~nm}$. (C) Incubation with Hsp70 did not impact the polymer mass observed per field $[p=0.18$ (Student's $t$ test)]. (D) There was a slight decrease in the number of $>200 \mathrm{~nm}$ aggregates, indicating that Hsp70 may have a subtle effect on the dissociation of tau filaments. Results are expressed as the mean \pm the standard error of the mean [ ${ }^{*} p<0.05$ (Student's $t$ tests)]. 
A

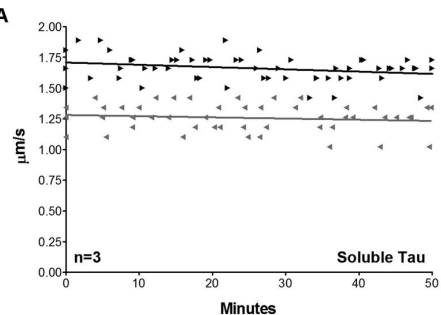

B

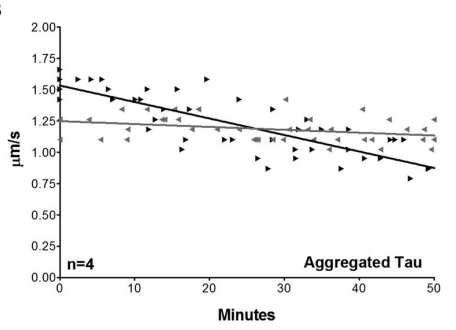

C

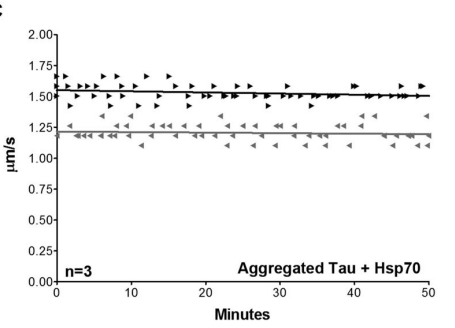

Figure 4.

Hsp70 rescues anterograde FAT in isolated squid axoplasm. Vesicle motility assays in isolated squid axoplasm. Individual velocity (micrometers per second) rate measurements (arrowheads) are plotted as a function of time (minutes). Black arrowheads and lines represent anterograde FAT rates (conventional kinesin-dependent), and gray arrows and lines represent retrograde FAT rates (cytoplasmic dynein-dependent). (A) Perfusion of soluble hTau40 $(2 \mu \mathrm{M})$ in axoplasm does not affect FAT. (B) Perfusion of tau aggregates (2 $\mu \mathrm{M})$ results in a select inhibition of kinesin-dependent FAT as previously reported. ${ }^{13}$ (C) When Hsp70 $(1.6 \mu \mathrm{M})$ is preincubated with the aggregated tau, no decrease in the velocity of anterograde FAT is observed [ $p<0.001$ (unpaired $t$ test)], indicating that Hsp70 reverses the toxicity of tau aggregates in isolated axoplasm. 

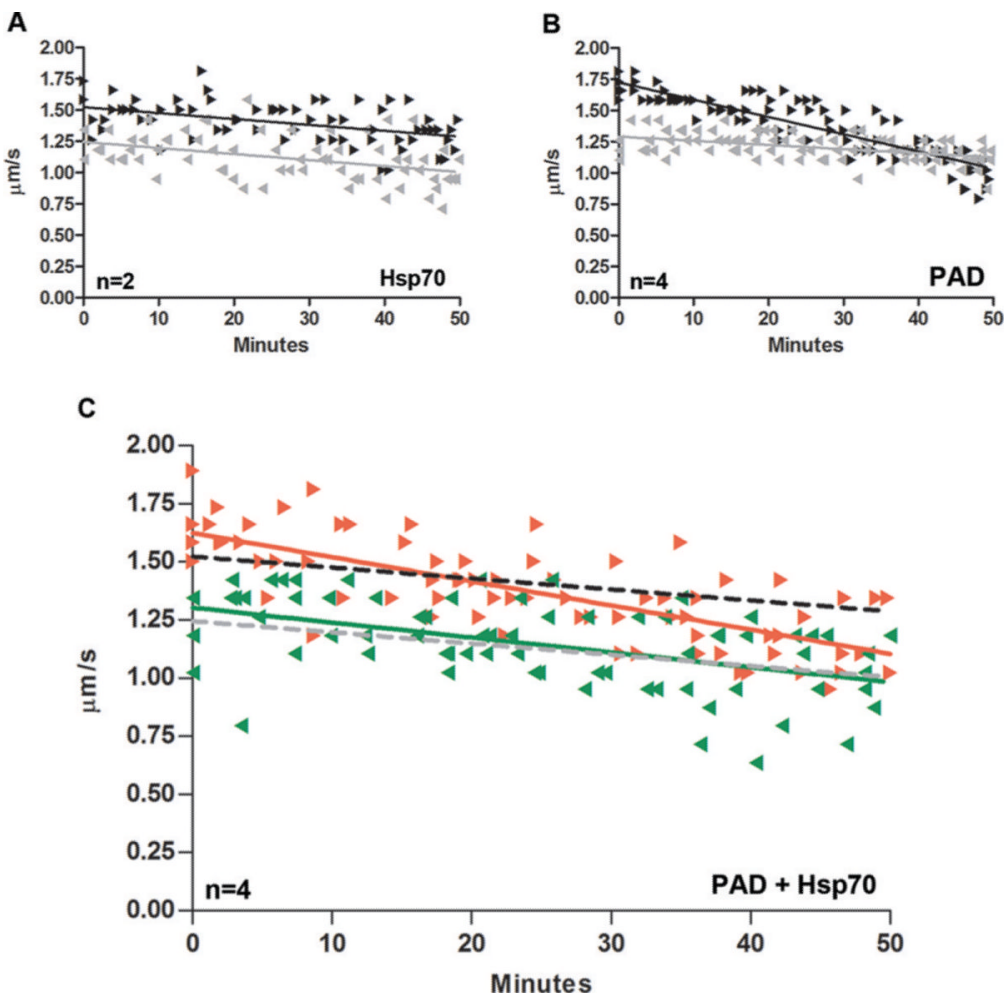

Figure 5.

Hsp70 does not rescue anterograde FAT when incubated with PAD peptide. Vesicle motility assays in isolated squid axoplasm. Individual velocity (micrometers per second) rate measurements (arrowheads) are plotted as a function of time (minutes). Black and red arrowheads and lines represent anterograde FAT rates (kinesin-dependent), and gray and green arrowheads and lines represent retrograde FAT rates (cytoplasmic dynein-dependent). (A) Perfusion of Hsp70 $(1.6 \mu \mathrm{M})$ alone in axoplasm has a mild inhibitory effect on both anterograde and retrograde FAT. (B) Perfusion of PAD peptide $(2 \mu \mathrm{M})$ results in a select inhibition of kinesin-dependent FAT as previously reported. ${ }^{15}$ (C) Co-incubation of Hsp70 $(1.6 \mu \mathrm{M})$ with PAD peptide does not alter the inhibitory effect of PAD on anterograde FAT [ $p=0.72$ (unpaired $t$ test)]. For comparison, dashed lines represent Hsp70 alone as shown in panel A; note that the green and gray lines representing retrograde transport are coincident in panel $\mathrm{C}$. 


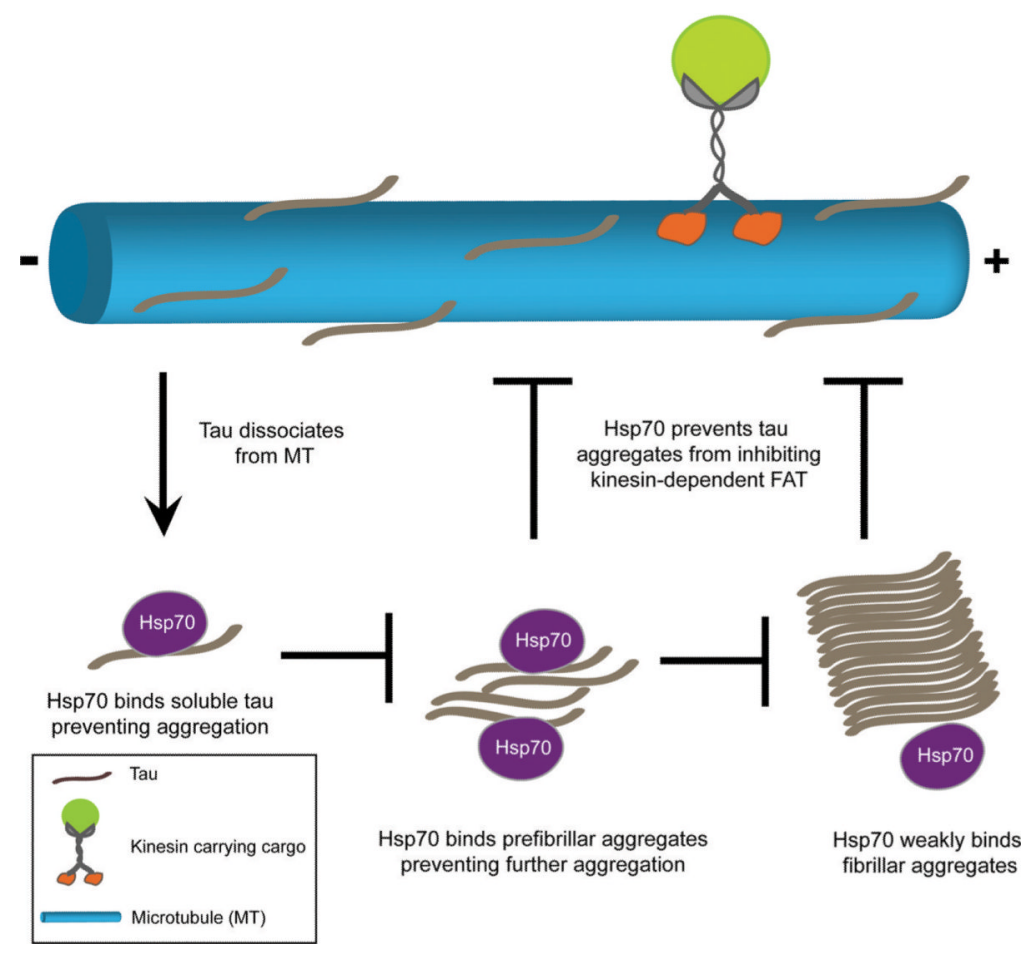

Figure 6.

Model of the effects of Hsp70 on tau dysfunction. Hsp70 binds soluble, monomeric tau that dissociates from microtubules, thus preventing self-association of tau into oligomeric and/or filamentous aggregates. In addition, Hsp70 also interacts with tau oligomers, ultimately preventing the formation of filamentous tau aggregates. Additionally, the association of Hsp70 with aggregated tau, particularly oligomeric tau aggregates, prevents activation of PP1 and GSK3 by the tau aggregates, preventing inhibition of conventional kinesindependent fast axonal transport. 


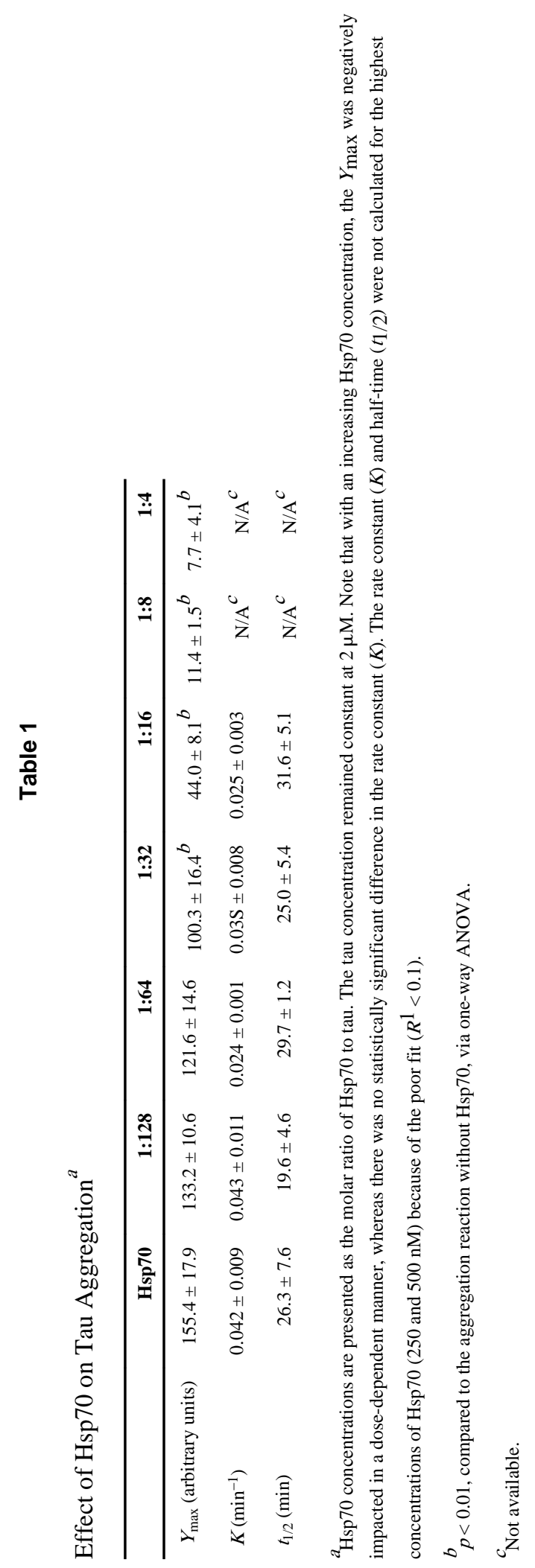

Biochemistry. Author manuscript; available in PMC 2012 July 02. 